\title{
TERRA-MERCADORIA NO AGRONEGÓCIO CEARENSE
}

\author{
the land-merchandise in the agrobusiness to the state of Ceará - Brazil \\ Tereza Sandra Loiola Vasconcelos* \\ Luiz Cruz Lima*
}

\begin{abstract}
Resumo
O texto analisa a utilização da terra como mercadoria, tendo como base empírica os lotes agrícolas do Perímetro Irrigado Baixo Acaraú. A terra do trabalho, da moradia e o lugar onde o homem realiza-se, constituída em grande parte por indígenas, artesões, pescadores e agricultores familiares camponeses, representa para os empresários do agronegócio instrumento onde o modo de produção capitalista pode reproduzir-se. Essa realidade não é recente, pois se anteriormente as terras às margens do rio Acaraú eram exploradas sob o pretexto da criação do gado, hoje essas mesmas terras constituem a rota da fruticultura. Para essas reflexões, foi realizada pesquisa entre os anos de 2008 a 2010, considerando-se, fontes documentais e bibliográficas, registros fotográficos e entrevistas. Esse é o enfoque das discussões presentes neste artigo: embasado na leitura da renda da terra em marx e nos dados referentes à movimentação capitalista dos lotes agrícolas, buscamos demonstrar como se dá a extração da mais-valia no Perímetro Irrigado Baixo Acaraú, no ensejo de transformar a terra do trabalho em terra do negócio.
\end{abstract}

Palavras-chave: Renda da terra, Perímetro Irrigado Baixo Acaraú, agronegócio cearense, mercado de terras.

\begin{abstract}
The text analyzes the use of the land-merchandise, having as empirical basis the agricultural lots of the Irrigated Perimeter "Baixo Acaraú". The land of the work, the housing and the place where the man becomes fulfilled, consisting to a large extent of indians, craftsmen, fishing and agriculturists peasants, represents for the entrepreneurs of the agrobusiness instrument where the way of capitalist production can multiply. This reality is not recent, therefore if previously the lands to the edges of the river Acaraú were explored under the excuse of the creation of the cattle, today these same lands constitute the route of the culture of fruits. For these reflections, a research was carried through between the years of 2008 and 2010, considering documentary and bibliographical sources, photographic registers and interviews. This is the approach of the discussions in this article: based on the reading of the income of the land (MARX, 1978) and on data referring to the capitalist movement of the agricultural lots, we tried to demonstrate how the extration of the more-value happens in the Irrigated Perimeter "Baixo Acaraú", transforming the land of the work into land of the business.
\end{abstract}

Key words:Income of the land, Irrigated Perimeter "Baixo Acaraú", agrobusiness to the State of Ceará, land market..

\section{Résumé}

Le texte analyse l'utilisation de la terre comme marchandise, ayant comme base empirique les lots agricoles du Périmètre Irrigué "Baixo Acaraú". La terre du travail, de la résidence et le lieu où l'homme se réalise, constituée en grande partie par des indigènes, artisans, pêcheurs et agriculteurs familiers des paysans, représente pour les entrepreneurs de l'agroaffaire un instrument où le mode de production capitaliste peut se reproduire. Cette réalité n'est pas récente, parce qu'autrefois les terres situées pres des bords de la rivière Acaraú étaient explorées sous le pretexte de l'élevage du bétail, aujourd'hui ces mêmes terres constituent la route de la culture des fruits. Pour ces reflexions, a été réalisée une recherche entre les années 2008-2010, considérant des sources documentaires et bibliographiques, des registres photographiques et des entrevues. Tout cela est le foyer des discussions présentes dans cet article: appuyé sur la lecture de la rente de la terre (MARX) et les informations concernants à la mouvimentation capitaliste des lots agricoles, on a cherché démontrer comme se produit l'extraction de la plus-value dans le Périmètre Irrigué "Baixo Acaraú", transformant la terre en marchandise, ou encore, dans le but de transformer la terre de travail en terre de l'affaire (MARTINS, 1991).

Mots-clés:Rente de la terre, Périmètre Irrigué “Baixo Acaraú”, agroaffaire d'État du Ceará, marché des terres.

(*) Doutoranda do Programa de Pós-Graduação em Geografia da Universidade Estadual do Ceará - Av. Paranjana, 1700 - Campus do Itaperi - CEP: 60.020-180. Fortaleza (CE) - Brasil, Tel.: (+55 85) 3101.9762 - terezaegageo@yahoo.com.br

(**) Prof. Dr. do Programa de Pós-Graduação em Geografia da Universidade Estadual do Ceará - Av. Paranjana, 1700 - Campus do Itaperi - CEP: 60.020-180. Fortaleza (CE) - Brasil, Tel.: (+55 85)3101.9762 - 1.cruzlima@uol.com.br 


\section{INTRODUÇÃO}

A atual modernização da agricultura cearense traz consigo problemas socioambientais, além de intensificar a concentração de terras, marca do período colonial, institucionalizada pelas antigas sesmarias. Para complementar a monocultura canavieira, nas bordas orientais do Nordeste brasileiro, a pecuária no semiárido despertou a cobiça dos especuladores de terras e dos pretendentes a fazendeiros, o que viria, com o tempo, solidificar-se como atividade econômica no Ceará, a partir do século XVIII. O século XIX é demarcado, por sua vez, pelos algodoais nas terras cearenses, consorciando-se com o criatório, ratificando, mais ainda, o poder econômico e político dos proprietários das grandes porções territoriais dos sertões cearenses. Nesses séculos, as grandes extensões de terras agrícolas sempre foram objeto de disputa dos poderosos, detentores dos melhores rincões, onde estivessem presentes solos férteis e água.

Com as inovações biotecnológicas, acompanhadas pela ideologia da "revolução verde ", se ampliaram as fronteiras da agricultura para abastecer os mercados norte-americanos e europeus, onde se encontram os maiores consumidores. No lugar em que se dispusesse de terras naturalmente férteis, as empresas agrícolas aí se assentariam, com a solicitude de um Estado benevolente e protetor. Esse é o retrato do que se denominou de agronegócio.

Os governantes locais, acompanhando as forças nacionais, se adequaram a essas demandas, com destaque na última década do século passado. Dessa forma, se ampliou a atividade do agronegócio, nas terras ensolaradas e atendidas pelo novo sistema de engenharia montado pelo Estado - os perímetros irrigados - para bem servir a esse tipo de empresas. Além disso, foram acionados meios para enfileirar um vasto exército de reserva de trabalhadores, surgido dos próprios habitantes das terras que iam sendo desapropriadas.

Os projetos de irrigação resultam do I Plano Nacional de Desenvolvimento (I PND), elaborado no governo Médici, na década de 1970. Muito embora construídos sob a justificativa de promover a reforma agrária e, ao mesmo tempo, modernizar a agricultura, por meio da colonização, já se percebia o incentivo à entrada de agroindústrias, no Plano Nacional de Irrigação (1979), o que se intensificou, posteriormente, no Ceará com as mudanças no seu quadro político local.

Após a ascensão de empresários ao governo, na segunda metade da década de 1980, os investimentos privados intensificam-se, fortalecendo-se com recursos externos, provindos do Banco Interamericano de Desenvolvimento - BIRD, em conjunto com o Ministério da Integração Nacional, como nos revela a informação do Distrito de Irrigação Baixo Acaraú - DIBAU, representante do Departamento Nacional de Obras Contra a Seca - DNOCS, e responsável pelo Perímetro Irrigado Baixo Acaraú:

A concepção do Perímetro Irrigado Baixo Acaraú, localizado na região Norte do estado do Ceará distando $220 \mathrm{~km}$ de Fortaleza e $160 \mathrm{~km}$ do porto de Pecém, tem uma posição privilegiada para exportação de seus produtos. Podendo alcançar à Europa ou Estados Unidos da América do Norte em 7 dias de navio ou 10 horas de avião. Para o mercado interno está interligado com a malha rodoviária nacional por rodovias asfaltadas. O Perímetro foi implantado por iniciativa do Ministério da Integração Nacional, o qual contou com a parceria do BIRD - Banco Interamericano de Desenvolvimento (www.baixoacarau. com.br).

O estado do Ceará, com quatorze perímetros irrigados, é líder no Nordeste, com esse tipo de agricultura tecnificada, destacando-se os Perímetros Irrigados Baixo Acaraú, Araras Norte, Jaguaribe-Apodi e Tabuleiro de Russas, símbolos de territórios de alta produtividade e celeiro de frutas tropicais para os mercados norte-americano e europeu. Diferentemente daqueles construídos durante a década de 1970, nesses, os investimentos tecnológicos, organizacionais e políticos direcionam-se ao crescimento do agronegócio, promovido por empresários, especuladores e multinacionais, beneficiados pelas políticas públicas voltadas a esse tipo de modernização da agricultura. 
O Perímetro Irrigado Baixo Acaraú, localizado entre as terras dos municípios cearenses de Acaraú, Bela Cruz e Marco, é um dos projetos pautados nesse modelo de atividade econômica, com ampla proteção às empresas, com menor interferência do Estado, que, para incluir a população em suas ideias neoliberais, utiliza-se do discurso de geração de emprego e renda, semelhante à fase da política do "Estado de Bem-Estar Social", em que a modernização da agricultura irrigada incluía a população local em seus objetivos, não desprezando a participação de empresas do agronegócio.

Os sistemas de engenharia, os recursos da informática, as pesquisas científicas laboratoriais e biotecnológicas, associados ao marketing agrícola, com a publicidade constante do projeto de irrigação, constituem algumas das características aparentes do perímetro irrigado, que apresenta na sua essência, uma intensa extração da renda fundiária, por meio dos proprietários capitalistas de terras.

A relação conflituosa do Perímetro Irrigado Baixo Acaraú estabelece-se, primordialmente, por se originar de política pública, sendo, no entanto, voltada aos interesses dos empresários da fruticultura, muitos deles não participando das comunidades locais, atingidas pelas desapropriações. Torna-se, assim, uma expulsão do homem da terra, para beneficiar os interesses exógenos. Essa realidade não é recente no Ceará, como demonstra a literatura (GIRÃO, 1995; GIRÃO, 2000; PINHEIRO, 2008). Se, anteriormente, as terras às margens do rio Acaraú eram exploradas para criação do gado, hoje essas mesmas terras constituem a rota do agronegócio e uma base empírica singular para a teoria da renda da terra (MARX, 1978).

Para essas reflexões, entre os anos de 2008 a 2010, realizamos pesquisa no intuito de entender a concepção e o funcionamento desse perímetro, como novo objeto geográfico que se adiciona à vida da sociedade cearense. Para tanto, demos atenção às fontes documentais e bibliográficas, aos registros fotográficos, apoiando as entrevistas com representantes do Estado, lideranças comunitárias, população local, trabalhadores rurais, agricultores familiares camponeses, além de empresários de estabelecimentos comerciais relacionados à agricultura irrigada e proprietários capitalistas de terra.

Essa é a base das discussões presentes neste artigo, como objetivo de compreender a leitura da renda da terra e da extração da mais-valia no Perímetro Irrigado Baixo Acaraú, com base nos dados referentes à movimentação capitalista dos lotes agrícolas, transformando a terra em mercadoria, ou ainda, no ensejo de transformar a terra do trabalho em terra do negócio (MARTINS, 1991), atendendo os preceitos divulgados pela "revolução verde".

\section{TERRA DO TRABALHO, TERRA DO NEGÓCIO NO BAIXO ACARAÚ}

No modo de produção capitalista, as relações natureza e sociedade e as relações entre os homens, são permeadas pela troca. É essa atmosfera que rege os espaços concentrados em capital, poder e terras; espaços selecionados, portanto estratégicos, onde há a estranheza entre o homem e a natureza, transformando-a em meio para produzir mais riqueza material.

Se a agricultura torna-se um investimento, visando à lucratividade, seu substrato, o solo, é visto como um meio para tal finalidade. Assim, a terra do trabalho essencial para a alimentação e moradia é apropriada por grupos capitalistas, metamorfoseando-a em terra do (agro) negócio, ou seja, mercadorias. É essa a compreensão de Martins (1991, p. 55), ao dizer:

Quando o capital se apropria da terra, esta se transforma em terra de negócio, em terra de exploração do trabalho alheio; quando o trabalhador se apossa da terra, ela se transforma em terra de trabalho. São regimes distintos de propriedade, em aberto conflito um com outro. Quando o capitalista se apropria da terra, ele o faz com o intuito do lucro, direto ou indireto. Ou a terra serve para explorar o trabalho de quem não tem terra; ou a terra serve para ser vendida por alto preço a quem dela precisa para trabalhar e não tem. Por isso, nem sempre a apropriação da terra pelo capital se deve à vontade do capitalista de se dedicar à agricultura. 
Dessa forma, a terra se transforma em mercadoria. Quando apropriada pelo capital, serve unicamente, para ser revendida ou utilizada para gerar produtos a serem repassados ao mercado. Esse processo é bem explicitado, quando Marx (1968, p. 06) nos diz:

Uma coisa pode ser um valor-de-uso e não ser um valor: basta que seja útil ao homem sem provir do seu trabalho. Assim acontece com o ar, prados naturais, terras virgens, etc. Uma coisa pode ser útil e produto do trabalho humano e não ser mercadoria. Quem, pelo seu produto, satisfaz as suas próprias necessidades, apenas cria um valor-de-uso pessoal [mas não uma mercadoria]. Para produzir mercadorias, tem não somente de produzir valores-de-uso, mas valores-de-uso para os outros, valores-de-uso sociais. [E não basta produzir para os outros. O camponês medieval produzia cereais para pagar o tributo ao senhor feudal e o dízimo à igreja. Mas nem o tributo e nem o dízimo, embora produzidos para outrem, eram mercadorias. Para ser mercadoria é necessário que o produto seja transferido para outrem, que o utilize como valor-de-uso, por meio de troca]. Finalmente, nenhum objeto pode ser um valor se não for uma coisa útil. Se é inútil, o trabalho que contém é gasto inutilmente [não conta como trabalho] e, portanto, não cria valor.

Para a formação de uma mercadoria, é necessário que as coisas produzidas e elaboradas pelo trabalho humano possuam utilidade, usufruídas pelas pessoas como valores de uso, a partir da troca mediada pelo capital, consolidando o processo de produção e circulação: fundamentos da mercadoria e da realização do sistema capitalista.

Todas as mercadorias possuem, agregados, valor de uso e valor de troca. A utilidade das coisas é essencial para que as pessoas sintam necessidade de comprá-las, trocando por um equivalente que chamamos de dinheiro. Nossas palavras se coadunam com às ideias de Marx (1968, p.2): “A mercadoria é, antes de tudo, um objeto exterior, uma coisa que, pelas suas propriedades, satisfaz necessidades humanas de qualquer espécie. Que essas necessidades tenham a sua origem no estômago ou na fantasia, a sua natureza em nada altera a questão".

A terra, como elemento da natureza, é essencial ao homem. Não provindo do seu trabalho, constitui valor de uso, assim como o ar e a água. Como objeto de trabalho, no intuito de satisfazer as suas necessidades imediatas de subsistência, produzindo apenas o que lhe é de fato necessário e sendo "lugar de moradia", a terra ainda não se configura como mercadoria, pois a busca por ela é voltada à satisfação de necessidades vitais ao organismo humano, logo, valor de uso.

Quando, porém, o valor de uso proporcionado pela terra desperta nos homens a possibilidade de ensejar lucro, a mediação passa a ser feita pelo dinheiro, pelo movimento de compra e venda (troca), resultando no final a mais-valia e a materialização da mercadoria. Basta que nos lembremos da clássica fórmula marxista: D-M-D', ou seja, dinheiro (D) para comprar terra (M) no intuito de acumular mais dinheiro (D) e reorientar esse movimento que é próprio do modo de produção capitalista.

A concretização da terra como mercadoria só é possível porque, de um lado, há os "donos" das terras, que se acham na condição de vendê-las para outros compradores, ou seja, de trocar a mercadoria por algo equivalente. Portanto, a propriedade privada da terra tem destaque nesse contexto. Para Marx (1978, p.p. 253- 257),

A propriedade da terra pressupõe o monopólio de certas pessoas sobre determinadas porções do planeta, sobre as quais podem dispor como esferas exclusivas de seu arbítrio privado, com exclusão dos demais. [...]. A propriedade da terra se distingue dos restantes tipos de propriedade pelo fato de que, uma vez alcançado certo nível de desenvolvimento se manifesta como supérflua e nociva.

Ampliando esse entendimento, Martins (1991, p. 54) nos chama atenção para os tipos de propriedades:

A propriedade capitalista é um regime distinto de propriedade. Baseia-se no princípio da exploração que o capital exerce sobre o trabalhador que já não possui os instrumentos e materiais de trabalho para 
trabalhar, possuídos agora pelo capitalista. Nesse caso, a propriedade capitalista é uma das variantes da propriedade privada, que dela se distingue porque é propriedade que tem por função assegurar ao capital o direito de explorar o trabalho; é fundamentalmente instrumento de exploração. Por isso não podemos confundir a propriedade capitalista com a propriedade familiar, ainda que propriedade privada. São coisas completamente diferentes, ainda que a passagem de uma para outra seja muito sutil e a muitos pareça não existir diferença alguma.

Com a exploração do trabalho, a propriedade capitalista gera mais capital, porque esse trabalho oferece excedente, produção acima do que é pago pelo dispêndio da energia do trabalhador.

Historicamente, no Brasil, o Estado tem influenciado esse processo de apropriação. Inicialmente com as sesmarias, em meados do século XVII, no Ceará, quando a terra era dividida entre aqueles que tinham ligações com a Coroa Portuguesa. Essa concessão representava recompensa por serviços prestados ao rei (como a expulsão e matança dos nativos, os indígenas) ou ainda por "qualidades" pessoais, expressas pelo status social do beneficiado na época, desde que para isso as terras fossem cultivadas (PINHEIRO, 2008).

No Nordeste, as zonas açucareiras representam as parcelas de terras entregues aos sesmeiros que logo tratavam de explorar o fértil solo litorâneo, acumulando riquezas materiais, em detrimento de uma população que vivia subserviente a esse processo, nas senzalas das casas grandes senhoriais (FREYRE, 1961).

No Ceará, a apropriação inicial das terras do vale do Acaraú ocorreu dessa forma, por meio de sesmarias, surgindo daí as primeiras famílias, formadas por vários portugueses ou ainda por pessoas provindas de Pernambuco, Maranhão e Piauí, servidas pelos habitantes da capitania cearense . Na pecuária, encontraram atividade eficiente para extrair das glebas de terras o poder financeiro e político que caracterizava os grupos dominantes da época, mediante a espoliação do trabalho dos habitantes locais, formados por índios, escravos ou por aqueles despossuídos de terra, ao que Pinheiro (2008) denomina de "pobres-livres". Com isso, o autor citado nos fala que

No Ceará, a situação era mais complexa socialmente; aqui se constituiu uma parcela que representava por volta de $10 \%$ da população, que eram os fazendeiros, criadores de gado, que detinham praticamente o monopólio da terra, um meio de produção essencial em uma economia agropecuária, mas também como um instrumento importante na construção das relações de poder. A condição de proprietário, criador de gado, escravista, definia a identidade social do setor dominante. (PINHEIRO, 2008, p. 21).

O sistema de sesmarias perdurou até 1824 quando, em 1850, como necessidade de regularizar as terras dos sesmeiros que ainda não tinham registros e expropriar os que ainda habitavam glebas úteis à produção comercial, foi criada a Lei de Terras, legalizando-se a propriedade privada daqueles que já a possuíam e instituindo a venda ou troca. A esse respeito, Silva (1996), referenciado por Reydon e Plata (2000, p. 34), complementa:

Em 1850, então, foi promulgada a Lei de Terras. Esta teria o objetivo de dentre outros fatores, proibir a aquisição de terras devolutas - terras pertencentes ao Estado, que não estivessem sendo utilizadas - que estivessem temporariamente e/ou ocasionalmente em mãos particulares. Com isso, visava não só regularizar as posses existentes, como também legalizar sua transmissão, sob a forma de compra e venda. Portanto, a Lei de Terras, de 1850, marca a possibilidade jurídica e institucional de ocorrência de negócios com terras e, consequentemente, aquele ano pode ser tomado como um marco na constituição dos mercados de terras rurais, quer dizer, a partir da vigência da Lei de Terras, constitui-se legalmente a propriedade privada da terra.

Na pecuária, evidenciaram-se as grandes divisões para formar as fazendas no interior do Ceará. As primeiras explorações das terras de Acaraú, Bela Cruz e Marco estão relacionadas a esse momento da história, por comporem o traçado do gado, às margens do rio Acaraú. 
Conforme os dados organizados por Pinheiro (2008), percebe-se como a pecuária influenciou na distribuição de sesmarias na capitania do Ceará, principalmente nas ribeiras do Acaraú e Jaguaribe. De acordo com o que se verifica na tabela 1 , a maior parte $(91 \%)$ das sesmarias solicitadas, entre os séculos XVII e XIX, tinha como justificativa a ocupação da terra com a atividade da pecuária ou ainda em consórcio com a agricultura, por considerar a terra como produtiva, assim como exigia o rei de Portugal.

Tabela 1: Distribuição de sesmarias na capitania do Ceará

\begin{tabular}{c|c|c|c|c}
\hline PERÍODO & PECUÁRIA & AGRICULTURA & $\begin{array}{c}\text { AGRICULTURA + } \\
\text { PECUÁRIA }\end{array}$ & TOTAL \\
\hline $1679-1699$ & 254 & - & 07 & 261 \\
\hline $1700-1709$ & 583 & - & 12 & 595 \\
\hline $1710-1719$ & 324 & 02 & 12 & 338 \\
\hline $1720-1729$ & 383 & 12 & 26 & 421 \\
\hline $1730-1739$ & 300 & 11 & 20 & 331 \\
\hline $1740-1749$ & 212 & 15 & 11 & 238 \\
\hline $1750-1759$ & 50 & 07 & 03 & 60 \\
\hline $1760-1769$ & 06 & - & - & 06 \\
\hline $1770-1779$ & 09 & - & 01 & 10 \\
\hline $1780-1789$ & 12 & 07 & 02 & 21 \\
\hline $1790-1799$ & 28 & 12 & 07 & 47 \\
\hline $1800-1809$ & 12 & 02 & 04 & 18 \\
\hline $1810-1819$ & 47 & 08 & 34 & 89 \\
\hline $1820-1824$ & 26 & - & 01 & 27 \\
\hline Total & 2246 & 76 & 140 & 2462 \\
\hline
\end{tabular}

Fonte: Cartas de sesmarias do Ceará - 14 volumes apud Pinheiro, 2008.

Essa forte ligação das ações promovidas pelos representantes do Estado com o mercado capitalista da terra ainda é bastante atual, porque eles permanecem como os responsáveis por normatizarem e regularem juridicamente essas vendas. Há, ainda, outros fenômenos nessa relação, quando, além de mediadores, esses representantes também são detentores de terras ou facilitadores para que essas posses sejam realizadas por grupos de capitalistas.

Os casos dos perímetros públicos de irrigação constituem exemplos típicos do que vem ocorrendo de forma cada vez mais intensa. Integrantes do Estado e empresários especuladores adquirem lotes agrícolas, utilizando-se de "laranjas", como são popularmente conhecidas aquelas pessoas que submetem seus nomes ao título da terra, no intuito de encobrirem os reais proprietários.

O trabalho de Silva (1989), sobre alguns perímetros do Nordeste, já denunciava essas estratégias:

Na prática, pode-se observar que não há fiscalização nem orientação da destinação dos lotes irrigados, pois até mesmo as disposições normativas e legais (que poderiam ser utilizadas para conter o processo de venda dos lotes) restam inaplicadas. Existe, por exemplo, a proibição de uma mesma pessoa ter mais de um lote em área de colonização, num mesmo perímetro, o que seria fundamental para impedir a reconcentração fundiária nos projetos públicos de irrigação. Entretanto, na prática, parecem existir vários atalhos para escapar a essa proibição como, por exemplo, via “testas-de-ferro". Por outro lado, nada impede que proprietários rurais de fora do perímetro adquiram os lotes que estão sendo vendidos. (p.p. 120-121)

Essas evidências estão presentes no Perímetro Irrigado Baixo Acaraú, evidenciando o duplo caráter das suas porções de terra: valor de uso e valor de troca (MARX, 1968). A utilização dos lotes 
agrícolas, dessa forma, demonstra a forte especulação, favorecida pelos organismos estatais, em uma política que se identifica como pública, proibindo a propriedade de mais de um lote agrícola de "pequeno produtor".

Analisando a relação dos lotes ativos - aqueles que estão sendo produtivos economicamente - em novembro de 2009, verificamos que dos 278 lotes, 53\% estavam em nome de "terceiros", ou seja, 148 porções de terras encobertas com titulações não condizentes com o que a realidade apresentava (figura 1).

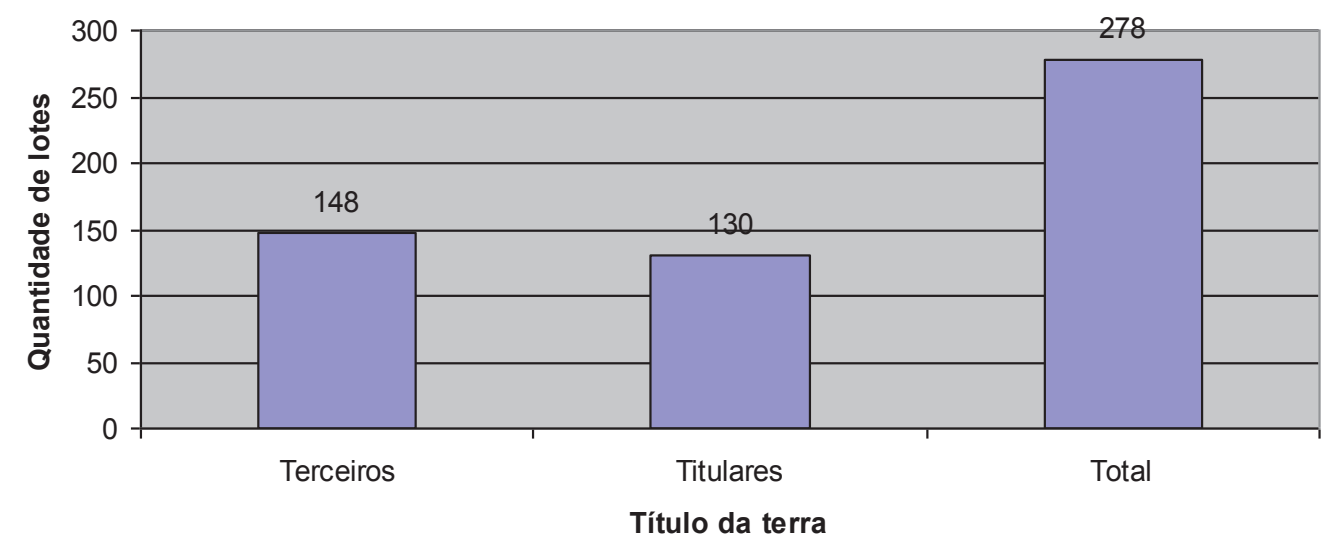

Figura 1: Posse dos lotes agrícolas ativos (novembro/2009).

Fonte: Vasconcelos, 2009.

O que a realidade mostrou, de acordo com a análise em campo, é que esses lotes em nome de "terceiros, laranjas ou testas de ferro", estavam sendo ocupados por profissionais ligados ao DNOCS, Banco do Nordeste - BNB, Secretaria de Agricultura do Ceará - SEAGRI, deputados, vereadores, ex-prefeitos e ainda por economistas, professores, advogados, engenheiros, dentre outros, ou seja, pessoas que possuem, como principal, outra atividade econômica.

Os intensos entrepostos, baseados nas vendas e compras de lotes agrícolas, muitas vezes passam "despercebidos" pela burocracia estatal e jurídica, fazendo com que vários proprietários realizem diretamente essas trocas, sem a intermediação jurídica, como nos relatou um funcionário do DIBAU, durante entrevista: “Alguns lotes já foram vendidos muitas vezes, tudo informalmente, nem sempre sabemos quando isso acontece, as negociações acontecem livremente no campo mesmo" .

Essa informação corresponde ao Estado mediador, detentor e conivente com o processo da terra-mercadoria, extraindo a mais-valia, que se efetiva com a propriedade privada .

Cabe ressaltar que a relação de lotes e produtores no perímetro irrigado não é estável, haja vista a intensa dinâmica dessa comercialização. É fato, por exemplo, a existência de lotes agrícolas, ainda em nome de "terceiros", que já foram repassados ao quarto proprietário .

Vários foram os motivos destacados por essas vendas. De um lado, alguns agricultores familiares que, em razão dos endividamentos com os bancos e o DNOCS, dadas as exigências técnicas e burocráticas da modernização os subjugaram à modernização da agricultura. De outro lado os verdadeiros especuladores, muitas vezes sem nenhum vínculo com a agricultura que, também por endividamentos, repassam os lotes a preços inferiores, dando significância à indagação feita por um agricultor: "Aqui tem muita gente que não sabe o que é agricultura. Se você é uma médica eu vou te dar uma enxada?" .

Cotidianamente, com esse mercado de terras, encontram-se, em torno do Perímetro de Irrigação Baixo Acaraú, anúncios de vendas de lotes agrícolas (figura 2).

Os lotes agrícolas representam a fragmentação do espaço, para torná-lo cambiável e consumido ao máximo possível. Essa realidade entra em consonância com os pensamentos de Lefèbvre 
(2008, p. 54),

Outrora, o ar e a água, a luz e o calor eram dons da natureza, direta ou indiretamente. Esses valores de uso entraram nos valores de troca; seu uso e seu valor de uso, com os prazeres naturais ligados ao uso, se esfumam; ao mesmo tempo em que eles se compram e se vendem, tornam-se rarefeitos. A natureza, como o espaço, com o espaço, é simultaneamente posta em pedaços, fragmentada, vendida por fragmentos e ocupada globalmente.

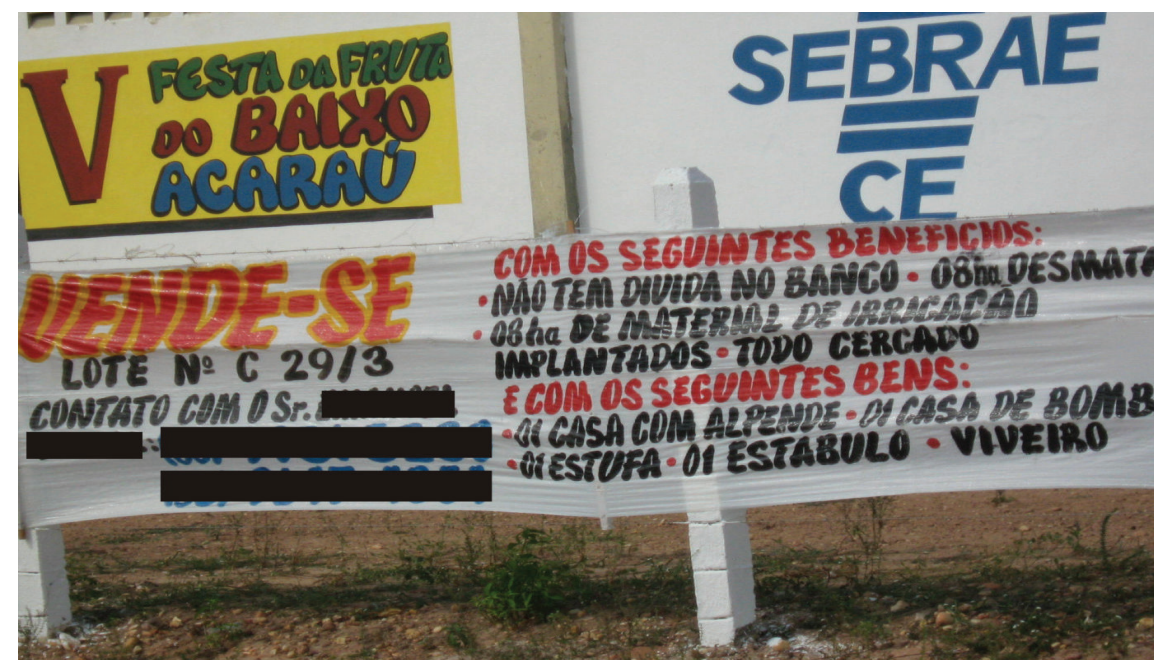

Figura 2: Venda de lotes agrícolas, em torno do Distrito de Irrigação Baixo Acaraú - DIBAU.

Um dos momentos propícios utilizados para a dinâmica das vendas é a Festa da Fruta, impulsionadora de novos investimentos no projeto, em que a planta do perímetro (figura 3), além de servir como direcionamento aos já produtores, serve de demonstração para novos investidores.

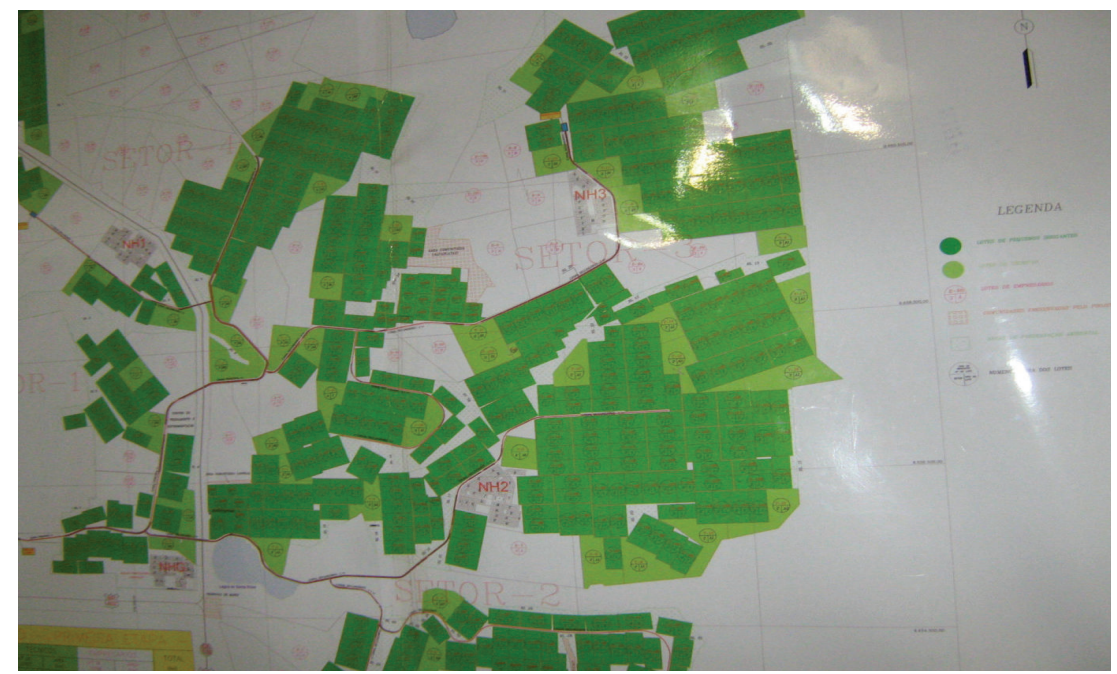

Figura 3: Planta do Perímetro Irrigado Baixo Acaraú, no escritório do DIBAU.

Nesse processo de venda, é fundamental a figura do comprador que utilizará a mercadoria como valor de uso ou como meio de transformá-la em mais dinheiro, acumulando capital, porquanto a 
terra tem propriedade específica de antecipar lucro permanente, assim tornando-se um investimento e proporcionando renda.

De acordo com Oliveira (2007), a renda da terra sempre existiu antes mesmo do modo de produção capitalista, motivo pelo qual se compreende que há a renda pré-capitalista e renda capitalista.

A renda pré-capitalista é retirada do produto excedente, portanto da produção. Há um contato direto entre o proprietário de terras e o agricultor, que cede parte de sua produção, necessária a sua subsistência, em troca das terras para o cultivo de seus produtos. Essa renda pode ser extraída em trabalho, produto e em dinheiro.

A renda em trabalho é a mais simples e mais antiga. Trata-se da renda extraída por meio da força e dos meios de trabalho que os agricultores sem terra ou com pouca terra dispõem, ao trocar seus trabalhos na produção das terras que não lhes pertencem pelo cultivo de alimentos para a sua família. Dessa forma, o capitalista recebe sem maiores esforços a terra arada e semeada, pronta para a transformação em produtos, e, por sua vez, em mercadorias, a qual (capitalista) transformará em mais dinheiro. A renda em produto é aquela em que o agricultor cede parte de sua produção ao proprietário por este ter concedido parcela de suas glebas para que o agricultor a cultivasse. A renda em dinheiro é a mais difundida. Trata-se do pagamento efetuado pelo agricultor ao proprietário de terras, pela sua utilização.

Observando os dados referentes ao censo agropecuário de 2006 (IBGE), percebemos que as rendas pré-capitalistas, à exemplo da "parceria" e do arrendamento, não se extinguiram no modo de produção capitalista, estando elas recriadas como formas encontradas pelos capitalistas de se reproduzirem e acumularem capital, explorando o agricultor familiar camponês sob diversas maneiras. No Nordeste brasileiro, o maior número de estabelecimentos de arrendatários localiza-se no Ceará, representando 36\%,conforme o quadro 1.

Quadro 1: Estabelecimentos (unidades) por categorias no Nordeste

\begin{tabular}{|l|l|l|l|l|l|l|l|l|l|}
\hline \multirow{2}{*}{ ESTABELECIMENTOS } & \multicolumn{10}{|c|}{ REPRESENTAÇÃO NO NORDESTE (\%) } \\
\cline { 2 - 13 } & MA & PI & CE & RN & PB & PE & AL & SE & BA \\
\hline Próprios & 7 & 8 & $\mathbf{1 1}$ & 3 & 7 & 13 & 5 & 5 & 40 \\
\hline Arrendatários & 24 & 14 & $\mathbf{3 6}$ & 2 & 5 & 7 & 5 & 1 & 6 \\
\hline Parceiros & 10 & 15 & $\mathbf{4 2}$ & 5 & 7 & 7 & 3 & 1 & 11 \\
\hline Ocupantes & 14 & 16 & $\mathbf{2 0}$ & 3 & 9 & 13 & 6 & 2 & 17 \\
\hline
\end{tabular}

Fonte: IBGE - Censo agropecuário, 2006.

As rendas diferencial I e II, absoluta e de monopólio, são tipos de rendas capitalistas. Constituem o lucro extraordinário, fração da mais-valia, que se realiza na circulação do produto agrícola e no pagamento na forma de salário, não equivalente ao que o capitalista acumulará no produto concretizado pelo trabalhador.

Os solos naturalmente mais férteis e mais bem localizados possibilitam extrair a renda diferencial I. Entrementes, a renda diferencial II é retirada daqueles solos que possuem investimentos em capitais (insumos agrícolas, maquinaria, equipamentos de irrigação etc.), utilizados para melhorar a sua fertilidade.

O elevado potencial hídrico que alimenta os lotes agrícolas, além do clima com intensa insolação e solos férteis, favoráveis ao cultivo da fruticultura, constituem atrativos para os produtores que investem no projeto de irrigação. A localização é outro fator que influencia na renda diferencial I, pois possibilita a velocidade na circulação dos produtos agrícolas e o retorno mais rápido, sob a forma de lucros ao produtor .

A proximidade do Perímetro Irrigado Baixo Acaraú com os principais mercados consumidores - Fortaleza, serra da Ibiapaba (especialmente a Central de Abastecimento/CEASA de Tianguá), 
Maranhão e Piauí - está associada às infraestruturas, como a estrada federal (BR 402) e, principalmente, ao complexo portuário do Pecém, situado na Região Metropolitana de Fortaleza, por onde escoam as frutas frescas.

Aqueles lotes agrícolas, artificialmente férteis, dotados de modernos sistemas de irrigação (microaspersão e gotejamento), de insumos agrícolas, fertilizantes e maquinaria, diminuem as perdas nas safras e, com isso, eleva-se a produtividade agrícola e acelera-se a circulação dos produtos, de onde é extraída a renda diferencial II, agregando-se à redução dos gastos com força de trabalho.

Assim, em um grupo de 56 proprietários capitalistas de terras , 83\% possuem ou já possuíram, pelo menos, quatro trabalhadores contratados mediantes as necessidades de cada proprietário. A contratação por lote agrícola varia entre um e 16 trabalhadores (tabela 2), que recebem o valor médio de $\mathrm{R} \$ 15,00$ por dia de trabalho.

Tabela 2: Trabalhadores rurais por proprietário capitalista de terra

\begin{tabular}{c|c}
\hline $\begin{array}{c}\text { TRABALHADORES } \\
\text { RURAIS }\end{array}$ & $\begin{array}{c}\text { QUANTIDADES DE PROPRIETÁRIOS } \\
\text { CAPITALISTAS }\end{array}$ \\
\hline $1-4$ & 29 \\
\hline $5-8$ & 13 \\
\hline $9-12$ & 4 \\
\hline $13-16$ & 1 \\
\hline Não possuem & 9 \\
\hline Total & 56 \\
\hline
\end{tabular}

O lucro extraordinário desses lotes agrícolas deriva-se justamente dessa espoliação do trabalhador que acumula mais funções e recebe bem menos do que seria possível, ante a alta produtividade obtida. No período da safra do melão, em três meses, somados os gastos com força de trabalho, transportes, insumos e fertilizantes, alguns proprietários capitalistas conseguem lucro acima da média, de $\mathrm{R} \$ 7.000,00$.

Essa não é a realidade de todos os proprietários de terra do perímetro irrigado. A concorrência entre eles vai estimular a renda diferencial, em que aquelas terras naturalmente férteis e com investimentos em capitais serão consideradas "melhores", ou seja, mais produtivas e, portanto, mais rentáveis.

A renda de monopólio também é lucro extraordinário, oriundo do preço de monopólio das mercadorias produzidas em terras com qualidades especiais. Os capitalistas, achando-se no poderio da propriedade, definem o seu preço e de seus produtos, elevando-os no mercado, quando assim o desejarem. Assim, a negociação da propriedade é determinada por quanto o consumidor está disposto a pagar e por quanto o capitalista estará satisfeito em receber. Ao contrário da renda absoluta, não está baseada em produtos essenciais, como os alimentícios. Além disso, enquanto a renda absoluta é extraída a partir dos custos de produção e pelo valor das mercadorias produzidas em propriedades privadas, é o preço ofertado pelos capitalistas ambiciosos pela terra que nutre a renda de monopólio.

Todas essas rendas capitalistas ensejam lucros extraordinários, suplementares e permanentes. Isso evidencia que no sistema capitalista a natureza que antes servia ao uso, às necessidades imediatas humanas, transforma-se em mercadoria, por meio da exploração do trabalho do agricultor, retirando a renda oferecida pela terra, na busca de satisfazer necessidades tornadas maiores, pois o homem aumentou a sua produção, à medida que atende interesses de mercado (MORAES e COSTA, 1984).

A terra, entretanto, é uma mercadoria especial. Ao contrário de outras mercadorias, não foi criada pelo trabalho humano, logo, seu preço é diferenciado. Não ocasionando capital imediato, ela é vista como potencial de renda capitalizada. Esta asserção condiz com os pensamentos de Reydon e Plata (2000, p. 44): 
Nesse contexto, o preço da terra enquanto ativo é o resultado das negociações entre compradores e vendedores no mercado de terras. O negócio é sempre feito quando o comprador tem expectativas mais elevadas sobre os ganhos futuros daquela terra do que o vendedor. Neste sentido, os movimentos das expectativas sobre os ganhos futuros advindos da terra, e portanto de seus preços, são as variáveis mais importantes para compreender a dinâmica do mercado de terras.

Na realidade, o que expressam esses autores é ratificado na seguinte entrevista com funcionário do DIBAU, acerca do preço dos lotes agrícolas do perímetro irrigado:

Na última licitação ocorrida em outubro/2008, foi cobrado R \$ 892,00 (oitocentos e noventa e dois reais) por hectare de terra nua, sem nenhum beneficiamento. Enquanto o valor praticado nas vendas de lote ocorridas em campo [lotes "revendidos"] depende de muitos fatores, entre eles se há algum beneficiamento no lote, localização do mesmo, a existência ou não de área de reserva legal influencia bastante, os débitos do lotes (que geralmente existem) com o Distrito [DIBAU], DNOCS ou BNB, e às vezes até a condição financeira do vendedor que o leva a vender o lote por valores bem abaixo do praticado normalmente. Mas, se fizermos uma média, o valor do lote sem beneficiamento fica mesmo nos $\mathrm{R} \$ 6.000,00$ (seis mil reais) [acréscimos nossos].

Assim, o preço da terra é definido pela renda que ela possa auferir, pela junção da quantidade de trabalho vivo - despendido na produção imediata - e de trabalho morto - contido nos meios de produção, mas também pela taxa de juros no mercado financeiro (MORAES e COSTA, 1984).

Silva (1989, p. 93) nos diz que

a subordinação da terra ao capital, transformando-se em ativo financeiro, faz com que seu preço passe a se formar a partir da interação de quatro determinantes gerais: as expectativas de ganhos produtivos com a terra; os movimentos da taxa de juros; as expectativas de valorização da terra e os gastos governamentais [referentes àqueles de organização ou administração da produção agrícola]. [acréscimo nosso].

Nesse processo, a especulação por meio da renda fundiária é expressa não apenas na realidade agrária, mas também urbana, como um desdobramento da intensa modernização da agricultura, nas áreas no entorno do perímetro irrigado (figura 4).

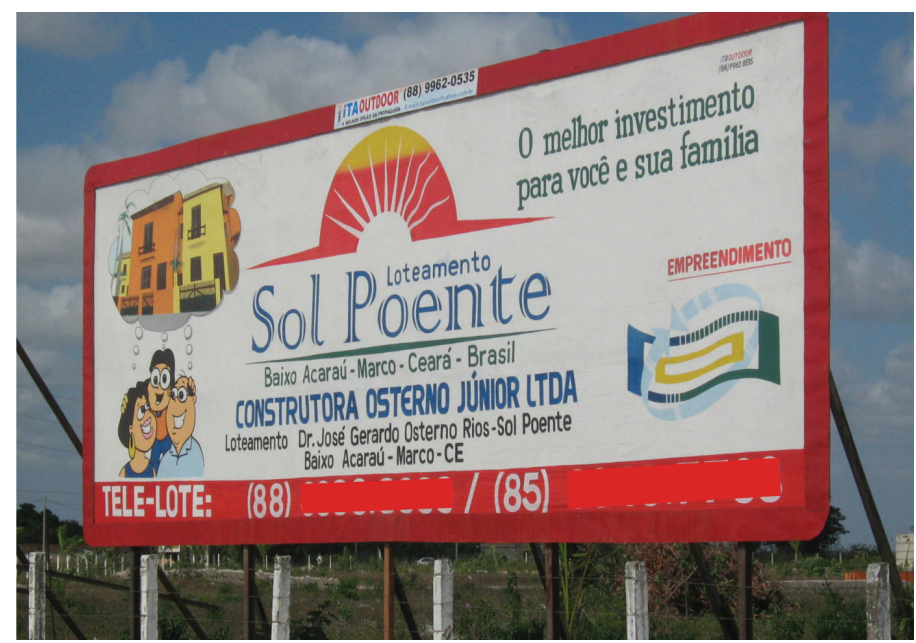

Figura 4: Especulação, por meio de lotes urbanizados no Município de Marco - CE.

Essa é a grande motivação que nutre o capitalista: a mais-valia proporcionada pela terra, não sendo exigência o fato de estar sendo produtiva para gerar a renda, o que configura a base da estrutura fundiária: a propriedade privada, estímulo para a concentração de terras e, por conseguinte, reserva para extrair e acumular capital. 
Nos projetos de irrigação, a concentração de lotes agrícolas é uma dessas evidências. Dos 278 lotes agrícolas ativos no Perímetro Irrigado Baixo Acaraú, em novembro de 2009, 45\% deles estavam concentrados entre 38 proprietários, utilizando-se de lotes agrícolas em nomes de "terceiros" (figura 5).

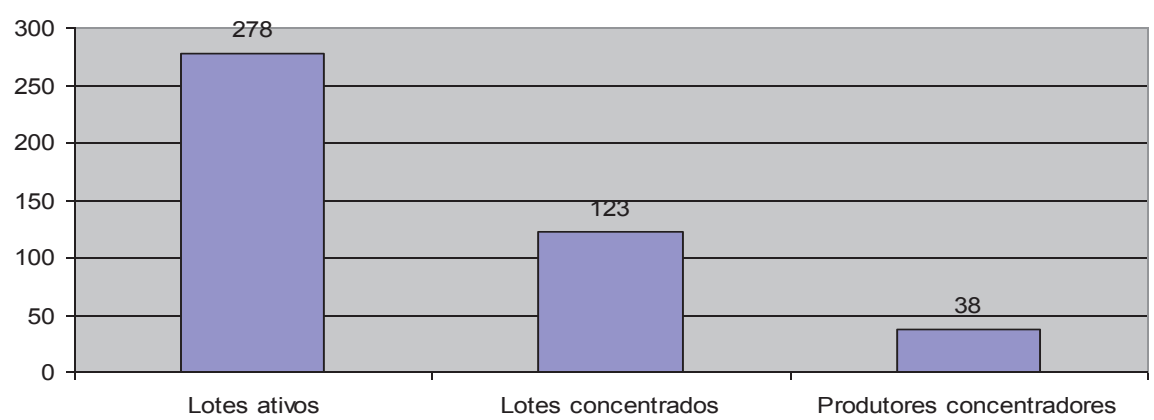

Figura 5: Concentração de lotes ativos no Perímetro Irrigado Baixo Acaraú (novembro/2009) Fonte: Adaptado por Vasconcelos (2009), com base nos dados do DIBAU.

A figura 6 demonstra a quantidade de lotes que cada proprietário desse grupo acumula, chegando um capitalista possuir 14 lotes agrícolas, configurando o uso da terra como renda capitalizada.

A maioria dos lotes abandonados no projeto de irrigação estava entre o grupo de especuladores, presentes na categoria de "pequenos produtores". De posse de pessoas sem vínculos com a agricultura, motivadas pela possibilidade do rápido lucro, os lotes agrícolas acabam sendo abandonados pouco tempo depois da compra.

Os dados revelaram que a concentração de lotes agrícolas e a especulação provêm do mercado de terras que se implantou nesse projeto de irrigação. A terra converteu-se em mercadoria, com maior destaque, por sua produtividade agrícola. Sobre isso, Silva (1989, p. 93) nos esclarece:

por estruturação do mercado de terras entende-se a sua conversão de um simples meio de produção (cujo preço é determinado em função da acumulação patrimonial e da produção de subsistência local) em uma mercadoria negociada em função de expectativas produtivas e especulativas de agentes que levam em conta, também, os retornos do mercado financeiro.

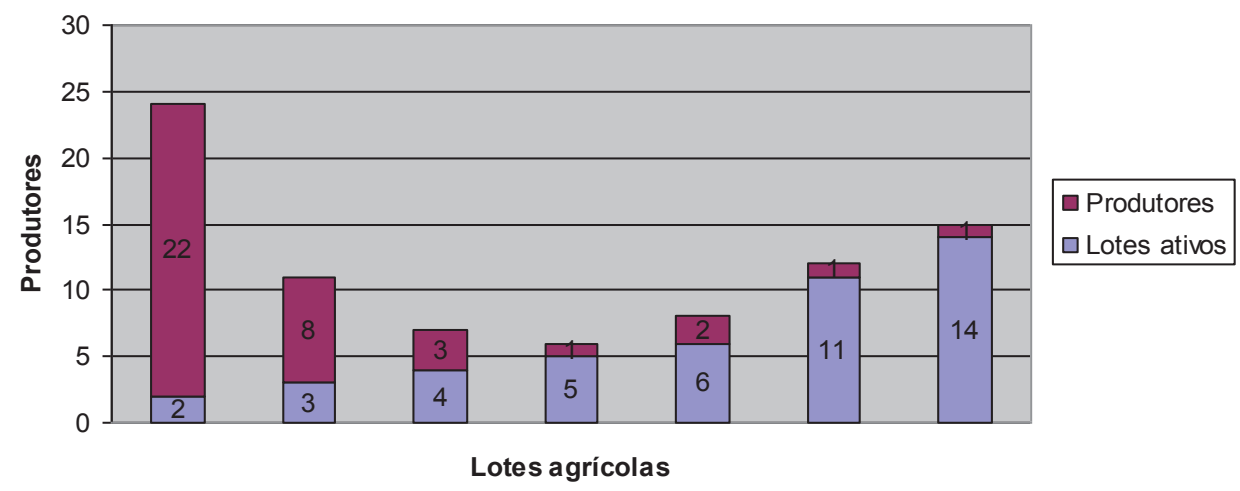

Figura 6: Concentração de lotes agrícolas ativos no Perímetro Irrigado Baixo Acaraú por proprietário (novembro/2009)

Fonte: Adaptado por Vasconcelos (2009), com base nos dados do DIBAU.

Assim, o elevado número de lotes em nome de "terceiros", as intensas trocas, muitas vezes ocorridas de forma direta, sem mediação estatal, a concentração de terras em um número reduzido 
de proprietários e, ainda, os lotes abandonados, são demonstrações da extração das rendas da terra, exemplificando a terra-mercadoria, forte e destacado problema social às margens do rio Acaraú, emblemática da atual modernização da agricultura cearense.

\section{CONSIDERAÇÕES FINAIS}

As relações conflituosas presentes no Perímetro Irrigado Baixo Acaraú muito se encaixam às palavras de Lampedusa, quando em seu romance (2003, pág. 42) o autor utiliza a expressão "se queremos que tudo fique como está, é preciso que tudo mude", ou ainda, em consonância com Martins (1991, p. 30): "o novo surge sempre como um desdobramento do velho".

Para tal compreensão fez-se necessário o percurso à história da produção do espaço cearense, quando se observa que essa parte do Nordeste sempre foi manipulada, atendendo aos interesses das classes dominantes, obedientes às ordens emanadas de outros países ou regiões do Brasil, em cada época. A aristocracia rural, com os criatórios de gado, às margens do rio Acaraú, intensificava seu poderio socioeconômico, em detrimento da distribuição de renda e melhorias sociais. Atualmente, são os empresários do agronegócio, com a atividade econômica da fruticultura, que ampliam seus domínios, apropriando-se de lotes agrícolas, expropriando a riqueza das comunidades locais, nesse processo de acumulação do capital no projeto de irrigação.

Percebemos que, embora as atividades econômicas alterem-se - pecuária, agricultura com o algodão, indústria, agronegócio - a terra permanece como possibilidade básica de gerar lucro permanente como instrumento de reprodução do capital, em detrimento do meio ambiente e das condições de sobrevivência do homem do local.

A construção do Perímetro Irrigado Baixo Acaraú veio legitimar o que historicamente consolidou-se nas terras situadas às margens do rio Acaraú: a extração da renda fundiária.

Além das terras serem naturalmente férteis e com boas localizações, para rápido escoamento da produção agrícola, a instalação de modernas infraestruturas e ofertas de créditos financeiros, com apoio do Estado e proporcionados pelos bancos, possibilitam aos proprietários capitalistas ampliarem seus lucros, cujos benefícios não se transformam em real qualidade de vida ao lugar. Com a especulação dos lotes agrícolas, os lucros ficam cada vez mais concentrados nas mãos de poucos e o discurso da "revolução verde" se "evapora", pois a elevação da produtividade agrícola não serve a mesa da população.

Com esse modelo de modernização da agricultura, em que se revela a terra-mercadoria exemplificada pelo Perímetro Irrigado Baixo Acaraú, se perpetua a concentração de terras, o que contradiz ao discurso sobre os perímetros irrigados e uma suposta reforma agrária, tão almejada pelos agricultores.

\section{REFERÊNCIA BIBLIOGRÁFICA}

ARAÚJO, Pe. Francisco Sadoc de. Raízes Portuguesas do Vale do Acaraú. Fortaleza: Gráfica Editorial Cearense Ltda, 1991.

BRASIL, Ministério do Interior: Departamento Nacional de Obras Contra as Secas. Lei $\mathbf{n}^{\mathbf{0}} \mathbf{. 6 . 6 6 2}$, de 25 de junho de 1970 - Dispõe sobre a Política Nacional de Irrigação, e dá outras providências. Fortaleza: Departamento de imprensa nacional, 1979.

FREYRE, Gilberto. Nordeste: aspectos da influência da cana sobre a vida e a paisagem do Nordeste do Brasil. $3^{\mathrm{a}}$ ed. Rio de Janeiro: Liv. José Olympio, 1961.

GIRÃO, Valdelice Carneiro. Da Conquista à Implantação dos Primeiros Núcleos Urbanos na Capitania do Siará Grande. In.: SOUZA, Simone (Coord.). História do Ceará. $4^{\mathrm{a}}$ ed. Fortaleza: Fundação Demócrito Rocha, 1995. p.p. $25-44$.

GIRÃO, Raimundo. História econômica do Ceará. Coleção Alagadiço Novo. $2^{\mathrm{a}}$ ed. Fortaleza: UFC, Casa de José de Alencar, 2000. 
LAMPEDUSA, Giuseppe Tomasi. O leopardo. São Paulo: Nova Cultura, 2003.

LEFÈBVRE, Henri. Espaço e política. Belo Horizonte: UFMG, 2008.

MARTINS, José de Souza. Expropriação e violência. A questão política no campo. $3^{\mathrm{a} e d . ~ S a ̃ o ~ P a u l o: ~}$ Hucitec, 1991.

MARTINS, José de Souza. O poder do atraso: ensaios de sociologia da história lenta. São Paulo: Hucitec, 1994.

MARX, Karl. O Capital: crítica da economia política. O Processo de Produção Capitalista. Livro 1, V.1. Rio de Janeiro: Edit. Civilização Brasileira, S.A., 1968. (versão digital).

MARX, Karl. A transformação da mais valia em renda da terra In.: O Capital: crítica da economia política. O processo global da produção capitalista. livro 3. São Paulo: Biblioteca do Pensamento Socialista, 1978. p.p. 252- 274 (versão digital).

MORAES, Antonio Carlos Robert; COSTA, Wanderley Messias da. Geografia crítica: a valorização do espaço. São Paulo: Hucitec, 1984.

OLIVEIRA, Ariovaldo Umbelino de. Modo de produção capitalista, agricultura e reforma agrária. São Paulo: Labur edições, 2007. (versão digital).

PINHEIRO, Francisco José. Notas sobre a Formação Social do Ceará (1680 - 1820). Fortaleza: Fundação Ana Lima, 2008.

REYDON, Bastiaan Philip; PLATA, Ludwig Agurto. Intervenção estatal no mercado de terras: a experiência recente no Brasil. Estudos do Núcleo de Estudos Agrários e Desenvolvimento Rural - NEAD. São Paulo: Unicamp, 2000.

RICARDO, David. Sobre a renda da terra. In.: RICARDO, David. Princípios de economia política e tributação. São Paulo: Editora nova cultural, 1996. p.p. 49-60 (versão digital).

136 SILVA, José Graziano da. (Org.). A irrigação e a problemática fundiária do Nordeste. Campinas: Instituto de economia; PRONI, 1989.

VASCONCELOS, Tereza Sandra Loiola. Reestruturação Socioespacial do Ceará: os desdobramentos da modernização da agricultura no território do Perímetro Irrigado Baixo Acaraú. Fortaleza, 2010. 188 pgs. Dissertação (Mestrado Acadêmico em Geografia) - Universidade Estadual do Ceará, Centro de Ciências e Tecnologia.

Trabalho enviado em maio de 2011

Trabalho aceito em julho de 2011 